\title{
«CREO, „SOCORRE MI FALTA DE FE!»: APROXIMACIÓN EXEGÉTICA AL RELATO DE CURACIÓN DEL MUCHACHO CON UN ESPÍRITU SORDO Y MUDO EN Mc 9,14-29¹
}

\section{“I do Believe, Help my Unbelief!": Exegetical Approach to the Healing of the Boy Possessed by a Mute Spirit in} Mark 9, 14-29

\section{"Creio! Vem em socorro à minha falta de fé!": Aproximaçáo exegética ao relato da cura do menino com um espirito surdo e mudo em Marcos 9,14-29}

\author{
Juan Alberto Casas Ramírez*
}

1 Artículo de investigación que plasma varios de los hallazgos del proyecto de investigación doctoral "Ciegos y sordos: clave hermenéutica del discipulado pospascual en el Evangelio según Marcos”.

* Doctor en Teología (2016), Magíster en Teología (2010) y Licenciado en Ciencias Religiosas (2008) de la Pontificia Universidad Javeriana, Bogotá- Colombia. Profesor e investigador de tiempo completo en el área de Teología Bíblica, Facultad de Teología, de la misma Universidad. Miembro de la Society of Biblical Literature y del grupo de investigación Didaskalia, reconocido por Colciencias. Correo electrónico: jcasas.smsj@ javeriana.edu.co

Artículo recibido el 2 octubre de 2015 y aprobado para su publicación el 1 marzo de 2016. 


\title{
Resumen
}

El relato de la curación del muchacho con un espíritu sordo y mudo (Mc. 9,1429), en el que la incomunicación entre el muchacho endemoniado y su padre contrasta con la comunicación entre Dios y su hijo (descrita en la perícopa precedente), sigue un patrón narrativo común con los relatos marcanos de curación en los que quienes padecen la afección tienen la condición de hijos/ hijas y quienes ejercen el rol de interceder, la de padres/madres. Aquí, el contraste entre la fe del padre intercesor (que posibilita la curación) y la poca fe de los discípulos (expresada en su fracaso al expulsar al espíritu) pone en evidencia el trasfondo discipular del relato.

\section{Palabras clave}

Teología bíblica, Evangelio según Marcos, Curación en la Biblia, Exorcismo en la Biblia, Discipulado.

\begin{abstract}
The narrative of the healing of the boy possessed by a mute spirit (Mark 9, 1429), in which the lack of communication between the possessed boy and his father contrasts with the communication between God and his Son-described in the previous pericope-, follows a shared narrative pattern with other healing narratives in the Gospel of Mark. This pattern has the following features: it is the sons and daughters who are affected by the illnesses, and it is the fathers and mothers who intercede for them. In this particular passage, it is the contrast between the intercessor father, who makes possible the healing, and the lack of faith of the disciples, expressed in their failure to expel the spirit, that reveals the discipleship nature of the narrative.
\end{abstract}

\section{Keywords}

Biblical Theology, Gospel of Mark, Healing in the Bible, Exorcism in the Bible, Discipleship. 


\section{Resumo}

O relato da cura do menino com um espírito surdo e mudo (Mc 9,14-29), no qual a incomunicaçáo entre o menino endemoniado e seu pai contrasta com a comunicação entre Deus e seu filho (descrita na perícope precedente), segue um padráo narrativo comum nos relatos marcanos de cura, nos quais quem padece a afecção tem a condição de filhos/filhas e quem exerce o papel de interceder, a de pais/mães. Aqui, o contraste entre a fé do pai intercessor (que possibilita a cura) e a pouca fé dos discípulos (expressa em seu fracasso ao expulsar o espírito) póe em evidência o fundo discipular do relato.

\section{Palavras-chave}

Teologia bíblica, Evangelho de Marcos, Cura na Bíblia, Exorcismo na Bíblia, Discipulado.

\section{INTRODUCCIÓN}

Retomando varios de los comentarios y estudios que se han desarrollado en torno al relato de la curación del muchacho poseído por un espíritu sordo y mudo (Mc 9,14-29), el presente artículo propone una aproximación exegética al texto a partir del desarrollo de tres postulaciones sucesivas, interdependientes y acumulativas. En primer lugar, se aborda el texto mismo de la perícopa a través de la explicitación de la crítica textual de la versión griega asumida, su estructura narrativa interna y su traducción, de corte literal. En segundo lugar se abordan los contextos narrativos del texto desde el punto de vista de su marco literario (en busca de conexiones y tensiones semánticas entre la perícopa y los relatos precedentes y subsecuentes) y desde el punto de vista de su marco narrativo (teniendo en cuenta el conjunto general de la trama del macro-relato evangélico). Finalmente, a partir del trayecto realizado, se analiza cada una de las escenas del relato tratando de dilucidar su sentido teológico que, como se constatará, pone en estrecha unión la cuestión cristológica del evangelio (relacionada con la pregunta ¿quién es Jesús?) con la cuestión discipular (relacionada con la pregunta ¿qué significa ser discípulo de Jesús?). 


\section{EL TEXTO: CRÍTICA TEXTUAL, ESTRUCTURA NARRATIVA Y TRADUCCIÓN²}

\begin{tabular}{|c|c|}
\hline $\begin{array}{l}\text { Texto griego } \\
\text { (Nestle \& Aland, 2012, pp 132-133; } \\
\text { Metzger, 2000, pp 154-155.) }\end{array}$ & Traducción literal al castellano \\
\hline A. Introducción: Vuelta de Jesús con "los tro & res" a la esfera pública (vv.14-16) \\
\hline 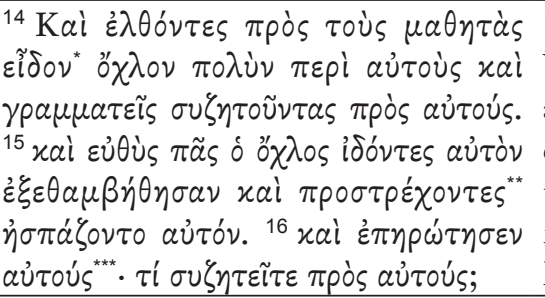 & $\begin{array}{l}{ }^{14} \text { Y volviendo hacia los discípulos } \\
\text { VIERON }{ }^{* * * *} \text { una gran multitud } \\
\text { alrededor de ellos y a los escribas } \\
\text { discutiéndoles. }{ }^{15} \mathrm{E} \text { inmediatamente } \\
\text { toda la multitud, VIÉNDOLE se } \\
\text { maravillaban, y corrieron a saludarle. }{ }^{16} \mathrm{Y} \\
\text { les preguntó qué discutían entre ellos. }\end{array}$ \\
\hline B. Conversación de Jesús con el padre del n & nuchacho (vv. 17-24) \\
\hline
\end{tabular}

2 Para distinguir la nomenclatura de las referencias al pie de los versículos bíblicos en el texto del presente relato la nomenclatura de las notas al pie aparecerá como subíndice.

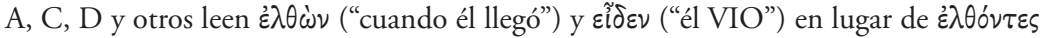
("llegando" o "cuando llegaron") y عĩdov ("VIERON"). Al respecto, el Comité de Crítica textual afirma que "la lectura en singular centra su atención en Jesús, mientras que la lectura en plural demanda que el lector distinga entre 'ellos' (esto es, Jesús, Pedro, Jacobo y Juan, a su regreso del monte de la transfiguración) y 'los discípulos' (esto es, los otros nueve que se habían quedado en el llano). Estas dos consideraciones internas llevaron al Comité de crítica textual a preferir la lectura que cuenta con el contundente apoyo de $\aleph$ B L W $\Delta \Psi 892$ et al" (Metzger, 2000, p. 85).

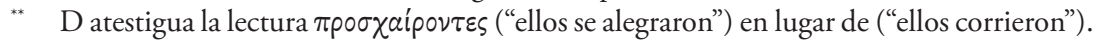
La primera lectura parece ser una corrupción temprana del texto (Collins, 2007, p. 433).

*** C, A, N y algunos otros no atestiguan la lectura ("a los escribas"). No obstante, la expresión es atestiguada en $\aleph$ y B (Nestle \& Aland, 2012, p. 132).

**** En Marcos aparecen, al menos, dos verbos de visión: por una parte, $\beta \lambda \varepsilon ́ \pi \omega$ (que hemos traducido como "ver") y por otra parte ópá $\omega$, que, al remitir al ejercicio de una visión de fe, más allá del "ver" sensorial o del "mirar/observar" intelectivo - $\theta \varepsilon \omega \rho \varepsilon ́ \omega ~-$, y ante la ausencia de un vocablo equivalente en castellano, hemos decidido traducido, a lo largo de todo el escrito, como "VER", y para distinguirlo del "ver" sensorial, lo hemos plasmado en mayúsculas fijas y con un tamaño de fuente un punto mayor que las demás (Noratto Gutiérrez, 2013). 


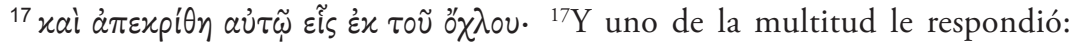

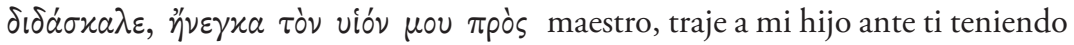

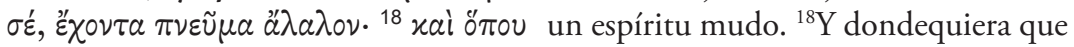

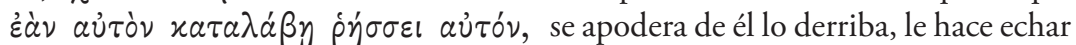

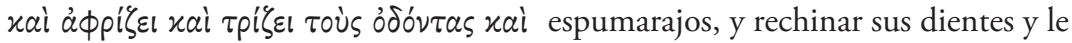

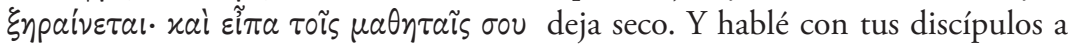

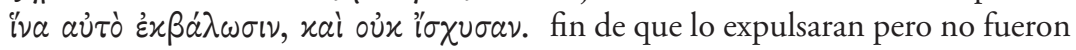

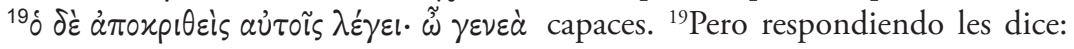

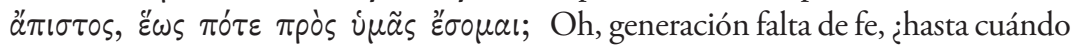

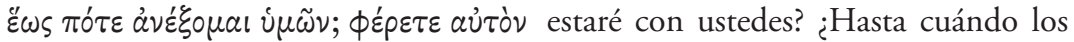
$\pi \rho o ́ s \mu \varepsilon$. soportaré? Tráiganlo ante mí.

${ }^{20}$ xai ク̆

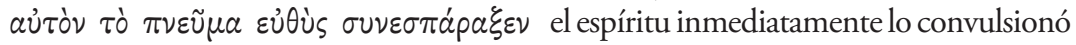

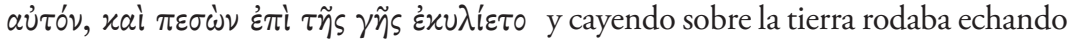

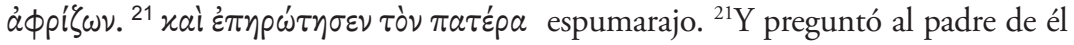

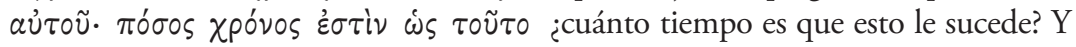

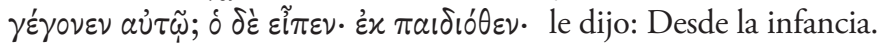

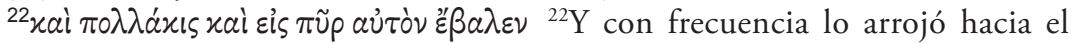

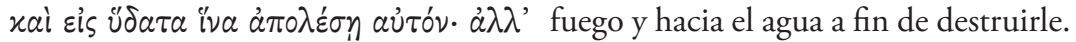

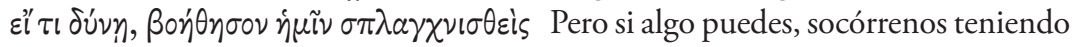

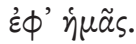
compasión sobre nosotros. ${ }^{23} Y$ Jesús le

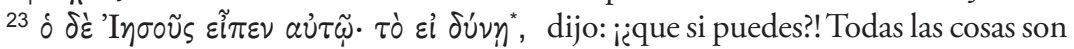

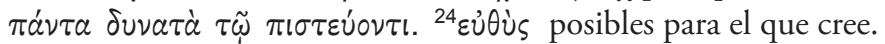

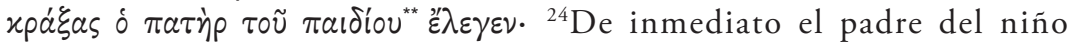

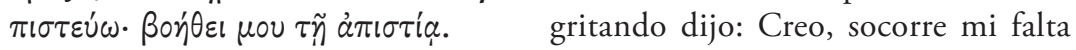
de fe.

* La extremada condensación de la oración ha representado problemas para los copistas.

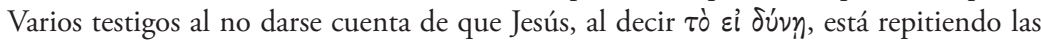

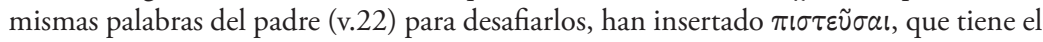
efecto de cambiar el sujeto del verbo 'poder' antes ligado a Jesús y ahora ligado al padre del muchacho. Con esto, la presencia de $\tau$ tò resulta más pedestre que nunca, por lo que muchos de estos testigos omiten la palabra” (Metzger, 2006, pp. 85-86).

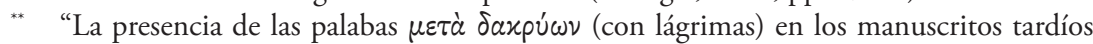
refleja una intensificación natural del relato, introducida por copistas y correctores. Ciertamente, de haber estado presente esta frase en el texto original, no habría ninguna razón de peso que explicara su omisión" (Ibid., p. 86). 


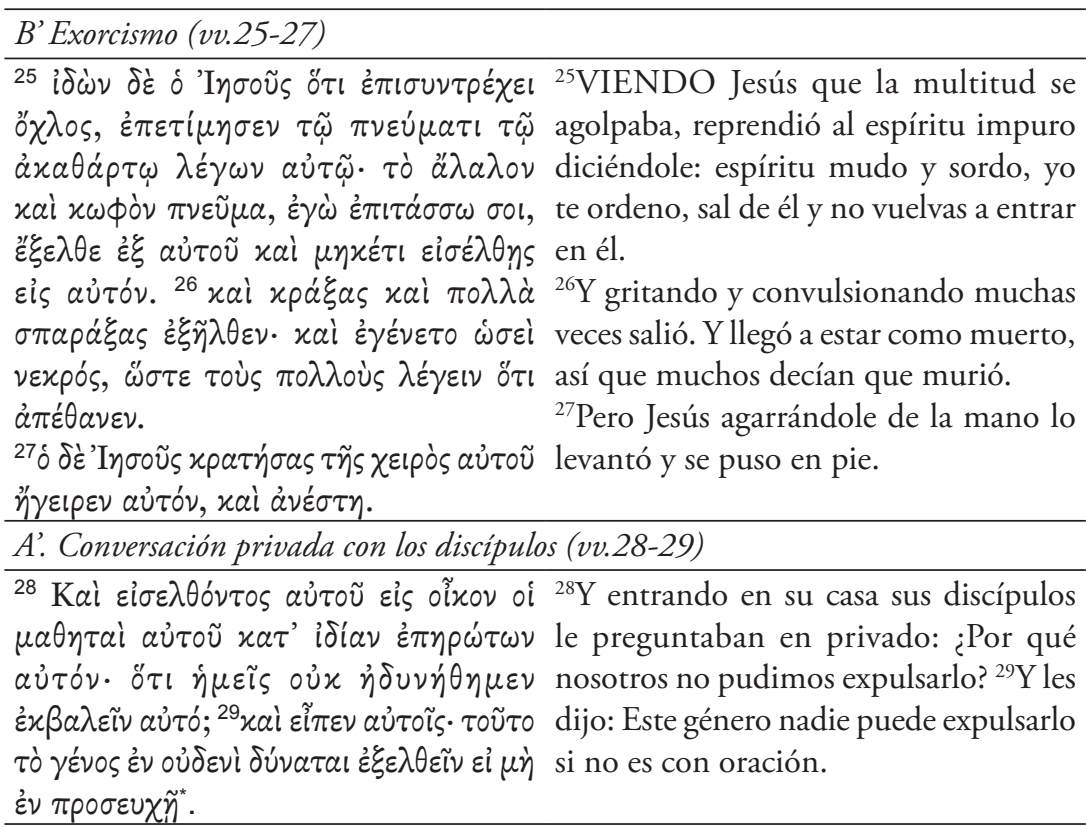

\section{CONTEXTOS: MARCO LITERARIO DEL TEXTO Y MARCO NARRATIVO DEL RELATO}

Mc 9,14-29 corresponde al segundo y último relato de curación-exorcismo

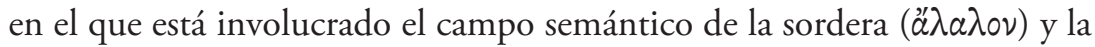

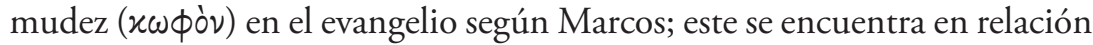
de paralelismo con el primer relato, de la "curación progresiva del sordo tartamudo" de 7,31-37, y teniendo en la mitad de ambos textos el primer

\footnotetext{
"Ante el énfasis cada vez mayor en la iglesia primitiva en cuanto a la necesidad de ayunar, puede entenderse que xai $\nu \eta \sigma \tau \varepsilon i ́ a$ sea una glosa que fue colándose en la mayoría de los testigos. Entre los testigos que se resistieron a tal adición se encuentran importantes textos representativos de los tipos textuales alejandrino y occidental" (Metzger, Ibid, p. 86). No obstante, como señala Maggi (2000, p.161), todo el versículo ya modificado "fue ańadido a Mt 17,20 decretando el éxito del ayuno como factor de expulsión de los demonios".
} 
relato de curación de un ciego, "el ciego de Betsaida", en 8,22-26. La perícopa se ubica en la primera de las tres secciones de la secuencia narrativa acontecida "en el camino" (8,27-10,52); dicha secuencia corresponde a la parte central del quiasmo del conjunto de la macro-narrativa evangélica, indicando, de esta manera, su importancia fundamental para la comprensión del resto del evangelio desde el punto de vista del develamiento de la identidad de Jesús como mesías sufriente que se dirige a Jerusalén para ser crucificado y luego resucitar, y de la identidad de los discípulos, llamados a seguirle mediante la negación de sí y el cargar con su propia cruz (cfr. Mc 8,34). Cada una de las tres secciones de esta secuencia posee una estructura tripartita compuesta por un anuncio "en el camino" ( $\dot{v} v \tilde{\eta} \tilde{\delta} \delta \tilde{\omega})$ por parte de Jesús a sus discípulos en torno a su pasión y su resurrección (8,31-32a; 9,30-32; 10,32-34), una reacción de incomprensión de estos en la que son descritos como si estuviesen "ciegos y sordos" ante las palabras del maestro, ya que se muestran más preocupados por otros intereses o con una perspectiva diferente sobre el mesianismo encarnado por Jesús (8,32b-33; 9,33-37; 10,35-40), y una serie de lecciones que Jesús dirige a los discípulos cuya extensión disminuye considerablemente con el paso de una sección a otra (8,31-9,29; 9,38-10,31; 10,41-45).

Es precisamente en el contexto de la "primera sección del camino" (8,31$9,29)$, en el marco de las lecciones a los discípulos (8,34-9,29), que se relata la curación del muchacho con un espíritu sordo y mudo $(9,14-29)$, seguida inmediatamente por el segundo anuncio de la pasión en 9,30-31, lo que indica que el sentido de la narración debe ser entendido, no solo como un texto de curación o exorcismo ${ }^{3}$, sino como parte del ejercicio educativo que Jesús pretende realizar (casi infructuosamente) con sus seguidores, por lo que el exorcismo estaría en función de la forma literaria de la "enseñanza" (prueba de ello es el diálogo en privado que tiene Jesús con los discípulos en los vv. 28-29 en torno a lo acontecido). Así, desde el punto de vista de la crítica de la redacción, tal parece que la narración correspondió originalmente a un relato de curación milagrosa, pero fue transformado en una instrucción

3 Como opina Collins (2007, p. 434): “Con respecto al género literario, el relato corresponde a un exorcismo, el cual es una sub-categoría de los relatos de curación o narraciones de milagros". 
para los discípulos ${ }^{4}$. En tal sentido, Moloney (2012, p. 183) considera que esta "forma mixta" de curación y enseńanza provee una conclusión a una serie de encuentros entre Jesús y sus frágiles discípulos $(8,32-9,29)$ después del primer anuncio de la pasión $(8,31)$.

En dicho marco narrativo, el relato viene precedido por las "condiciones para seguir a Jesús" dirigidas tanto a la multitud como a los discípulos ( $\tau \dot{o} v$

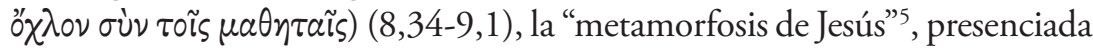
por "los Tres" (Pedro, Santiago y Juan) (9,2-8), y la discusión entre "los Tres" con Jesús sobre el sentido de "resucitar de entre los muertos" y de la "venida de Elías" (9,9-13). Como se observará, una de las claves de comprensión del relato de 9,14-39 es su parangón con las palabras emitidas por "la voz desde el cielo" (en 9,2-8) en las que se indica quién es el Hijo, el amor que se le profesa y el imperativo de que los discípulos deben escucharle sólo a él ${ }^{6}$. En contraste, al bajar de la montaña, se presenta a un padre incomunicado con su hijo a quien los discípulos no pueden ayudar (¿por no escuchar al Hijo?). En el mismo relato de 9,14-29 la indicación de los protagonistas también será una marca textual. Así, en 9,14, junto a los escribas y a los demás discípulos, vuelve a hacer su aparición la multitud, descrita aquí como

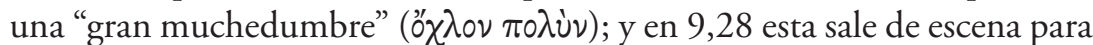

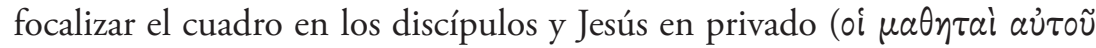
$\varkappa a \tau$ ' idíl $\nu$ ). De este modo, la secuencia correspondiente a las "lecciones a los

$4 \mathrm{Al}$ respecto, Bultmann (2000, pp. 211-212) encuentra una serie de características incoherentes que le llevan a sugerir el entrecruzamiento de varias tradiciones: "la multitud parece venir a Jesús dos veces (vv. 15.25) y hay dos descripciones de la afección (vv. 1718. 22). Algunos sugieren que las dos tradiciones han sido puestas juntas y esta sería la causa de la repetición".

5 Tradicionalmente se habla en castellano de la "transfiguración" de Jesús. No obstante,

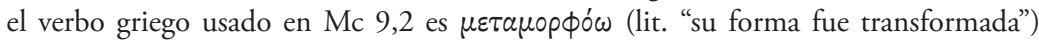
que, transliterado al español adquiere un sentido más amplio al expresarse como "metamorfosis" más que como "transfiguración" (Al respecto ver el estudio de Prieto Fernández, 2009).

$6 \mathrm{Al}$ respecto, Ruis-Camps (2008, p.187) opina que las palabras emitidas por "la voz desde el cielo" y el diálogo posterior sobre la venida de Elías, buscan "corregir la mentalidad de los discípulos, imbuidos por el magisterio de los letrados sobre el papel que Elías debía representar en la manifestación del Mesías $(9,11)$, delimitando certeramente quién es el verdadero intérprete del proyecto de Dios: 'Este es mi Hijo, el amado, jescuchadle a él, a él! $(9,7) ”$. 
discípulos" de 8,34-9,29 podría organizarse de la siguiente forma de acuerdo con el criterio de los personajes y los escenarios que son mencionados:

\begin{tabular}{|c|c|c|}
\hline \multicolumn{3}{|c|}{ Primera serie de "lecciones de Jesús a los discípulos" $(8,31-9,29)$} \\
\hline Escena & Personajes & Escenario \\
\hline $\begin{array}{l}\text { 1. "Condiciones para } \\
\text { seguir a Jesús" }(8,34-9,1)\end{array}$ & $\begin{array}{l}\text { Jesús, multitud y } \\
\text { discípulos. }\end{array}$ & $\begin{array}{l}\text { "En el camino", en } \\
\text { las aldeas de Cesarea } \\
\text { de Filipo (según la } \\
\text { indicación de 8,27). }\end{array}$ \\
\hline $\begin{array}{l}\text { 2. "Metamorfosis de } \\
\text { Jesús" }(9,2-8)\end{array}$ & $\begin{array}{l}\text { Jesús, Elías, Moisés y } \\
\text { "Los Tres". }\end{array}$ & Un "monte alto" $(9,2)$. \\
\hline $\begin{array}{l}\text { 3. Discusión sobre } \\
\text { el sentido de la } \\
\text { resurrección y la venida } \\
\text { de Elías }(9,9-13)\end{array}$ & $\begin{array}{l}\text { Jesús y "Los Tres" } \\
\text { (mención a los escribas } \\
\text { en v.11) }\end{array}$ & $\begin{array}{l}\text { "bajando del monte" } \\
(9,9)\end{array}$ \\
\hline $\begin{array}{l}\text { 4. "Curación-exorcismo } \\
\text { del muchacho con } \\
\text { espíritu sordo y mudo" } \\
(9,14-27\end{array}$ & $\begin{array}{l}\text { Jesús, "los Tres”, demás } \\
\text { discípulos y multitud, } \\
\text { escribas, padre del } \\
\text { endemoniado y } \\
\text { endemoniado }\end{array}$ & 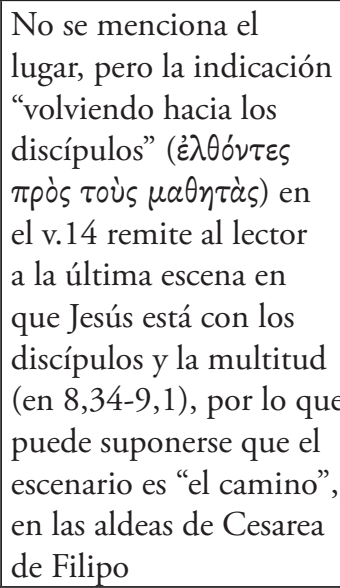 \\
\hline $\begin{array}{l}\text { 5. "Enseñanza privada } \\
\text { sobre la curación- } \\
\text { exorcismo del muchacho } \\
\text { con espíritu sordo y } \\
\text { mudo" }(9,28-29)\end{array}$ & $\begin{array}{l}\text { Jesús y los discípulos en } \\
\text { privado }\end{array}$ & $\begin{array}{l}\text { "Al interior de la casa" } \\
(\text { (Eis oĩxov) }(9,28)\end{array}$ \\
\hline
\end{tabular}

Nótese la relación existente entre las escenas 1 y 4 en que la mención de la bina "multitud-discípulos" se registra a modo de quiasmo antitético (multitud-discípulos en 8,34, y discípulos - multitud en 9,14). Asimismo, 
al final de la primera escena, en 8,38, Jesús hace mención de "esta generación

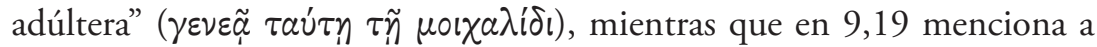
la "generación incrédula" ( $\gamma \varepsilon \nu \varepsilon \dot{\alpha} \alpha \ddot{\pi} \iota \sigma \tau ం \varsigma)$. Nótese también que entre las escenas 2, 3 y 5 , existe en común el carácter privado (y, por lo mismo, exclusivo) de la enseñanza de Jesús a los discípulos (a "los Tres" en 9,2-13, y "en privado", "en la casa" en 9,28-29). A este respecto, se establece una relación de paralelismo narrativo entre las escenas 2 - 3 y 4 - 5: Mientras las escenas 2 y 4 describen un acontecimiento (la "metamorfosis de Jesús" y el "exorcismo del muchacho"), las escenas 3 y 4 describen un diálogo privado entre Jesús y los discípulos profundizando en el sentido de los acontecimientos precedentes. Además, la mención a los escribas en el v.11, en el contexto de la discusión sobre la venida de Elías mientras Jesús y "los Tres" bajan del monte se encontraría conectada con la enunciación de aquellos discutiendo con los demás discípulos en el v.14 (no obstante, en dicho versículo no se menciona la causa de la discusión).

De igual modo, no puede perderse de vista la relación literaria entre este relato de exorcismo y los exorcismos que se han narrado desde el inicio en la macro-narrativa evangélica ya que el conjunto de estos posee elementos comunes que Marcus (2010) señala a continuación:

Cada una de las cuatro primeras secciones principales del evangelio contiene un exorcismo importante: el endemoniado en la sinagoga de Cafarnaún en la sección primera (1,21-28); el endemoniado geraseno en la sección segunda (5,1-20); la hija de la mujer sirofenica en la sección tercera $(7,24-30)$ y el muchacho epiléptico, aquí en la sección cuarta. Los dos primeros exorcismos afectan a endemoniados adultos; el primero a un judío y el segundo a un gentil. Los dos siguientes afectan a endemoniados infantiles; el primero, a un gentil y el segundo a un judío; en el primero de estos dos últimos la madre de la muchacha poseída intercede por ella, mientras que en el segundo el padre del muchacho poseído intercede por él. En ambos casos la curación va precedida por una discusión con los escribas $(7,1-15 ; 9,14)$. En ambos casos Jesús retrasa la curación y esta tardanza está relacionada con la situación de la generación presente $(7,27 ; 9,19.21 a)$. En ambos casos, sin embargo, el progenitor persiste en la súplica y la curación va ligada a la fe manifestada por el progenitor $(7,29 ; 9,23-24)$. (p. 747) 
Resulta igualmente sugestivo encontrar un patrón narrativo común con respecto a los relatos marcanos de curación en los que quienes padecen

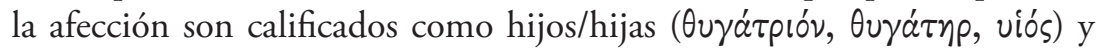
quienes ejercen el rol de interceder por el enfermo son sus padres/madres o, al menos, como en el caso de Bar Timeo, el nombre del padre es mencionado en relación con la identidad del hijo. Tales casos son: "La hija de Jairo" (5,21-24.35-43), "La hija de la Siro-fenicia" (7,24-30), "el hijo del padre suplicante" (9,14-29) (que corresponde al relato que nos ocupa), y "al hijo de Timeo (Bar-Timeo)" (10,46-52). Con un matiz especial en el último (Bar-Timeo), en todos estos casos los padres/madres realizan unos gestos dramáticos de súplica pidiendo la curación y, para acrecentar el dramatismo, aparece también un grupo antagonista que obstaculiza la intercesión. El siguiente esquema recoge los elementos enunciados:

\begin{tabular}{|c|c|c|c|c|}
\hline Escena & $\begin{array}{c}\text { Hija de Jairo } \\
(5,21-24.35- \\
43)\end{array}$ & $\begin{array}{c}\text { Hija de la } \\
\text { Siro-fenicia } \\
(7,24-30)\end{array}$ & $\begin{array}{c}\text { Hijo del padre } \\
\text { suplicante } \\
(9,14-29)\end{array}$ & $\begin{array}{c}\text { Hijo de } \\
\text { Timeo y el } \\
\text { hijo de David } \\
(10,46-52)\end{array}$ \\
\hline Escenario & $\begin{array}{l}\text { Orilla judía } \\
\text { del mar. Se } \\
\text { menciona } \\
\text { la casa en } \\
5,35.38\end{array}$ & $\begin{array}{l}\text { Región de } \\
\text { Tiro. Se } \\
\text { menciona } \\
\text { la casa en } \\
7,24.30 \text {. }\end{array}$ & $\begin{array}{l}\text { Galilea. Se } \\
\text { menciona la } \\
\text { casa en 9,28. }\end{array}$ & $\begin{array}{l}\text { Salida de } \\
\text { Jericó }\end{array}$ \\
\hline Intercesor/a & $\begin{array}{l}\text { Padre } \\
\text { (Jairo, Jefe de } \\
\text { Sinagoga) }\end{array}$ & $\begin{array}{l}\text { Madre } \\
\text { (pagana, } \\
\text { Sirofenicia de } \\
\text { nacimiento) }\end{array}$ & $\begin{array}{l}\text { Padre, de entre } \\
\text { la gente }(9,17)\end{array}$ & $\begin{array}{l}\text { El ciego grita } \\
\text { pidiendo } \\
\text { compasión. } \\
\text { La multitud } \\
\text { que lo quiere } \\
\text { acallar } \\
\text { después le da } \\
\text { ánimo. }\end{array}$ \\
\hline
\end{tabular}




\begin{tabular}{|c|c|c|c|c|}
\hline Escena & $\begin{array}{c}\text { Hija de Jairo } \\
(5,21-24.35- \\
43)\end{array}$ & $\begin{array}{c}\text { Hija de la } \\
\text { Siro-fenicia } \\
(7,24-30)\end{array}$ & $\begin{array}{c}\text { Hijo del padre } \\
\text { suplicante } \\
(9,14-29)\end{array}$ & $\begin{array}{c}\text { Hijo de } \\
\text { Timeo y el } \\
\text { hijo de David } \\
(10,46-52)\end{array}$ \\
\hline $\begin{array}{l}\text { Antagonistas } \\
\text { que } \\
\text { obstaculizan } \\
\text { la intercesión }\end{array}$ & $\begin{array}{l}\text { Los que } \\
\text { llegan de la } \\
\text { casa de Jairo } \\
\text { informándole } \\
\text { de la muerte } \\
\text { de la hija y la } \\
\text { no necesidad } \\
\text { de "molestar } \\
\text { al maestro" } \\
(5,35)\end{array}$ & $\begin{array}{l}\text { Jesús mismo } \\
\text { al pedirle a } \\
\text { la mujer que } \\
\text { esperase a } \\
\text { "que primero } \\
\text { se sacien los } \\
\text { hijos, pues } \\
\text { no está bien } \\
\text { tomar el pan } \\
\text { de los hijos y } \\
\text { echárselo a los } \\
\text { perros" (7,27) }\end{array}$ & $\begin{array}{l}\text { Escribas que } \\
\text { discuten con } \\
\text { los discípulos } \\
(9,14) \text { y los } \\
\text { discípulos } \\
\text { mismos que } \\
\text { no pueden } \\
\text { expulsar } \\
\text { el espíritu } \\
(9,18.28) \text {. }\end{array}$ & $\begin{array}{l}\text { La multitud } \\
\text { que rodea } \\
\text { a Jesús que } \\
\text { increpa al } \\
\text { ciego para } \\
\text { que se calle } \\
(10,48)\end{array}$ \\
\hline $\begin{array}{l}\text { Acciones de } \\
\text { intercesión }\end{array}$ & $\begin{array}{l}\text { - Cae a los } \\
\text { pies de Jesús } \\
\text { (v.22). } \\
\text { - Suplica a } \\
\text { Jesús por su } \\
\text { hija que está } \\
\text { a punto de } \\
\text { morir. } \\
\text { - Jesús le pide } \\
\text { tener fe }\end{array}$ & $\begin{array}{l}\text { - Sus palabras } \\
\text { sobre las } \\
\text { migajas de } \\
\text { los niños } \\
\left(\pi \alpha ı \delta^{\prime} \omega \nu\right) \text { a } \\
\text { los perros } \\
\text { producen el } \\
\text { exorcismo. }\end{array}$ & $\begin{array}{l}\text { - Lleva al hijo } \\
\text { ante Jesús. } \\
\text { - Relata la } \\
\text { sintomatología } \\
\text { de la posesión. } \\
\text { - Grita } \\
\text { pidiendo fe. }\end{array}$ & $\begin{array}{l}\text { - Pide } \\
\text { compasión. } \\
\text { - A pesar de } \\
\text { la reprimenda } \\
\text { de la gente, } \\
\text { grita más } \\
\text { fuerte. } \\
\text { - Pide ver. }\end{array}$ \\
\hline $\begin{array}{l}\text { Acciones de } \\
\text { Jesús }\end{array}$ & $\begin{array}{l}\text { - Toma la } \\
\text { mano de la } \\
\text { nińa }(5,41) \\
\text { - Le ordena } \\
\text { que se levante } \\
\text { y ella se pone } \\
\text { en pie }(5,41 \text { - } \\
42)\end{array}$ & $\begin{array}{l}\text { - Dice a la } \\
\text { mujer "Por } \\
\text { lo que has } \\
\text { dicho, vete, el } \\
\text { demonio ha } \\
\text { salido de tu } \\
\text { hija" }(7,29)\end{array}$ & $\begin{array}{l}\text { - Toma al } \\
\text { muchacho de } \\
\text { la mano. } \\
\text { - Lo levantó y } \\
\text { se puso en pie } \\
(9,27)\end{array}$ & $\begin{array}{l}\text { - Dice a } \\
\text { Bar Timeo } \\
\text { "Vete, tu fe } \\
\text { te ha salvado" } \\
(10,52) .\end{array}$ \\
\hline $\begin{array}{l}\text { Destinatarios } \\
\text { de la } \\
\text { intercesión }\end{array}$ & 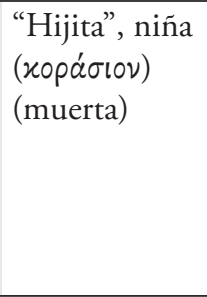 & $\begin{array}{l}\text { Hija (poseída } \\
\text { por un } \\
\text { espíritu } \\
\text { inmundo) }\end{array}$ & $\begin{array}{l}\text { Hijo, } \\
\text { muchacho } \\
\text { ( } \pi \text { aı́íov) } \\
\text { (poseído por } \\
\text { un espíritu } \\
\text { sordo y } \\
\text { mudo). }\end{array}$ & $\begin{array}{l}\text { Hijo de } \\
\text { Timeo (ciego, } \\
\text { mendigo) }\end{array}$ \\
\hline
\end{tabular}




\title{
3. EL RELATO DE MC 9,14-29: DESARROLLO DE LA SECUENCIA NARRATIVA
}

\author{
A. Introducción: Vuelta de Jesús con "los tres" a la esfera \\ pública (vv.14-16)
}

El relato inmediatamente precedente en que Jesús desciende del monte junto con "los Tres", después de la experiencia de la "metamorfosis" (en que la identidad y destino de Jesús son puestos en relación con Moisés y con Elías) (Mc 9,9-13), aporta el marco comprensivo del relato de exorcismo: como Moisés, Jesús acaba de descender del monte después de haber tenido una experiencia teofánica en la que su rostro quedó resplandeciente (cfr. Ex 34,29; 2Cor 3,7.13). No obstante, como señala Marcus (2010),

en el Éxodo el pueblo tiene miedo de acercarse a Moisés, mientras que en Marcos corre hacia Jesús y lo saluda. Pero en el pasaje del Éxodo el pueblo vence finalmente el miedo y se acerca a Moisés. Es posible que el presente relato desee mostrar una comparación así como un contraste: el resplandor de Moisés era aterrador, mientras que el temor hacia Jesús era a la vez atemorizante y atractivo (...). [Además, comparado con la vuelta de Moisés del Sinaí (Ex 32)], en ambos casos, al bajar, el personaje ve un espectáculo terrible marcado por la continua presencia del pecado y de la dureza de corazón en un mundo que, sin embargo, está en el camino de la redención. (p. 746 y 754)

El escenario presenciado por quienes descienden de la montaña es dramático: los escribas se encuentran discutiendo con los discípulos mientras la multitud les rodea. Con seguridad (como se infiere del v.17), el motivo de la discusión gira en torno a la imposibilidad de efectuar el exorcismo del muchacho cuya aparición narrativa será en la siguiente escena. No es de extrañar, como ya se ha indicado, que en el pasaje inmediatamente anterior Pedro, Santiago y Juan traigan a colación la opinión de los escribas sobre la venida de Elías (Mc 9,11). Se extiende, así, un puente semántico entre el presente relato y el primer exorcismo del evangelio, en 1,21-28 en que la enseñanza de Jesús se distingue de la de los escribas en razón de su autoridad, lo que lleva a autores como Maggi (2000) a afirmar que la posesión estaría relacionada con el seguimiento de la enseńanza de los escribas: 
La primera vez que en el Evangelio de Marcos aparece un 'hombre con un espíritu inmundo', se indica que la causa de su impureza es la adhesión a la doctrina de los escribas (Mc 1,21-28). La última vez que en el mismo evangelio se presenta una intervención de Jesús ante un espíritu inmundo, de nuevo este está en relación con los escribas, responsables de endemoniar al pueblo. (p. 156)

Asimismo, habría también una conexión con el episodio de 3,20-30 en que los escribas atribuyen el poder exorcista de Jesús a la acción de Belcebú (consideración que ocasionará su posición en el grupo de "los de fuera" en 4,10-12). Al respecto, Marcus (2010) afirma que,

La actitud hostil de los escribas es similar a la manifestada por ellos en 3,20, donde reconocían el poder exorcístico de Jesús pero lo atribuían al Demonio. Así pues, los escribas marcanos condenan a Jesús y a sus discípulos tanto si exorcizan como si no, por lo que Marcos tendería probablemente a atribuir esa constante hostilidad a una fuente demoniaca. (p. 753)

Por otra parte, la llegada de Jesús genera un cambio abrupto por parte de

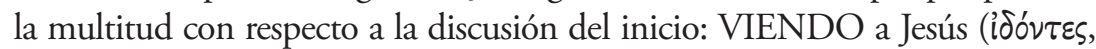
en participio aoristo), se maravillaban ( $\xi \xi \varepsilon \theta \alpha \mu \beta \eta \dot{\eta} \theta \eta \sigma \alpha v)$ y corrieron a saludarle. Llama la atención que en el v.15 no se menciona el motivo para justificar la

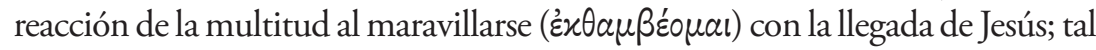
parece ser, como señala Collins (2007, p. 437), que este es un recurso literario para resaltar el significado y la autoridad de Jesús (como en 1,27). De hecho, la emoción de la muchedumbre ante la llegada de Jesús es expresada con el verbo $\dot{\varepsilon} x \theta \alpha \mu \beta \varepsilon^{\prime} \omega$, que aparece en otros relatos marcanos con referencia a las fuertes emociones de Jesús en Getsemaní $(14,33)$ y la confusión de las mujeres al encontrar la tumba vacía en la mañana de pascua $(16,5.6)$. Asimismo, como observan Donahue y Harrington (2002, p. 277), las acciones de la multitud corriendo hacia Jesús y saludándole evocan las acciones del hombre rico en 10,17.

\section{B. Conversación de Jesús con el padre del muchacho (vv.17-24)}

Tal pareciera que la complejidad narrativa de esta parte del relato expresa la existencia de más de una tradición en el proceso de su composición. Por ello, autores como Byrne (2008) consideran que la historia misma es 
laberíntica y compleja puesto que la multitud parece llegar dos veces (v.15 y v.25); la "patología" asociada con la posesión del muchacho se describe en detalle dos veces (v. 18 y vv.21b-22a); y los escribas mencionados al inicio (v.14) no juegan un papel posterior. Así, "el desnivel es probable debido a la dependencia de Marcos de más de una tradición" (Ibid., 2008, 149).

Teniendo en cuenta la existencia de esta complejidad, en una primera instancia, ante la pregunta de Jesús sobre la razón de la discusión, la intervención del padre del muchacho al llamar a Jesús "maestro" ( $\delta 1 \delta a ́ \sigma \varkappa a \lambda \varepsilon)$ y señalar que ha traído su hijo ante él establece una relación analógica entre la enseñanza autoritativa de Jesús y el poder de exorcizar (mencionado ya en la trama evangélica en 1,21-28). No se puede perder de vista que, hasta ahora, en Marcos, Jesús ha sido llamado "maestro" solo dos veces, en 4,38 y en 5,35. A medida que la narración avance, este título se incrementará con mayor frecuencia (cfr. 9,38; 10,20.35; 12,14.19.32; 13,1; 14,14) (Donahue \& Harrington, 2002, p. 277). La idea de trasfondo, según Collins (2007, p.437), es que en el caso de Jesús, tanto la autoridad para enseñar como el poder de exorcizar tienen un origen divino.

A continuación, de acuerdo con la descripción del padre sobre la afección del hijo en el v.17, el demonio que posee al muchacho es llamado "un espíritu mudo" ( $\pi \nu \varepsilon \tilde{u} \mu \alpha a ̈ \lambda \alpha \lambda \circ \nu)$. Juzgando por el resto del relato, la razón es que aquí, a diferencia de las otras narraciones de exorcismos, el espíritu no habla a través de la persona poseída; en este caso la posesión sólo es manifestada por sus síntomas físicos. Comparado con los primeros exorcismos donde los demonios hablan e identifican a Jesús como "el santo de Dios" $(1,24)$ y como el "Hijo del altísimo" $(5,7)$, el espíritu que posee al muchacho lo hace incapaz de hablar y es mudo (ä $\lambda \alpha \lambda \circ v)$ (Donahue \& Harrington, 2002, p. 277). La descripción que da el padre sobre los ataques del muchacho es vívida: el espíritu "le derriba, le hace echar espumarajos, rechinar de dientes y le deja rígido" (v.18). El síntoma final ("le deja rígido")

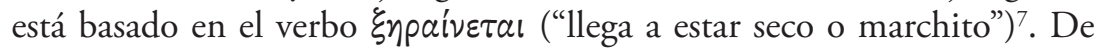

7 Esta raíz es empleada en Marcos para referirse al "hombre que tenía una mano seca"

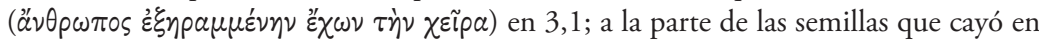

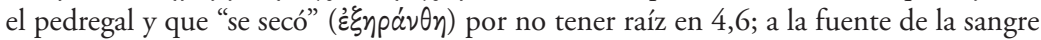
que "se secó" ( $\dot{\xi} \xi \eta \rho \alpha ́ v \theta \eta)$ en la mujer con hemorragia en 5,29, y a la higuera que Jesús

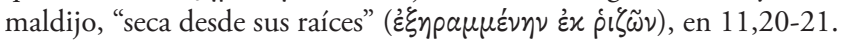


hecho, siguiendo a Collins, la descripción de la acción del espíritu puede derivar de una antigua percepción de los síntomas de la epilepsia, la cual era vista en la cultura griega como una visita divina al punto de considerársele

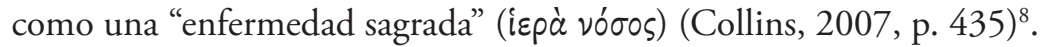

Después de la primera descripción de la acción del espíritu, el padre refiere a Jesús el fracaso de los discípulos para efectuar el exorcismo. Dicho fracaso es reminiscencia de la ineficiencia de Guejazí para resucitar al hijo de la sunamita en los ciclos de Elías y Eliseo (cfr. 2R 4,31) ${ }^{9}$. Al escuchar el intento frustrado de exorcismo, la exclamación-reclamo de Jesús acerca de la "generación sin fe" ( $\gamma \varepsilon v \varepsilon \dot{\alpha} \alpha \ddot{\pi} \iota \sigma \tau \varsigma \varsigma)$, como ya se ha mencionado, evoca a la "generación adúltera" de 8,32 y, al mismo tiempo, se relaciona con 9,29 en que Jesús se refiere al "género" ( $\gamma \varepsilon ́ v 0 \varsigma$ ) de espíritus inmundos que sólo puede ser expulsado mediante la oración ${ }^{10}$. No obstante, la referencia a la "generación falta de fe" resulta ambigua ya que no se especifica quiénes son los destinatarios. La queja puede estar dirigida a los escribas, cuya presencia aquí es inexplicable y fugaz; a los discípulos, bajo el supuesto de que su incapacidad para expulsar el espíritu se debió a su falta de fe; o al padre, cuya propia fe sería insuficiente para que el exorcismo tuviera lugar (Collins, 2007, p. 437). Al respecto, Moloney

8 De acuerdo con el tratado hipocrático, Sobre la enfermedad sagrada, algunas personas trataban de curar la epilepsia a través de la "purificación y la magia". Además, las convulsiones epilépticas eran asociadas con la influencia de la luna, de ahí que la descripción del texto paralelo de Mateo 17,15 refleje tal asociación al decir que el niño era lunático

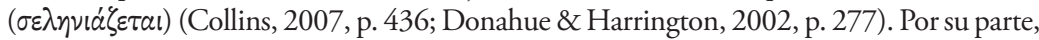
Marcus (2010, p.747) asevera que "en el paganismo antiguo la epilepsia era denominada a menudo la «enfermedad sagrada» (morbo sacro), aunque no hubiera unanimidad sobre la causa de esta denominación; algunos pensaban que era así porque la enfermedad era enviada por una divinidad; otros, porque atacaba a los que habían pecado contra un dios, y otros finalmente porque sólo podía ser curada por intervención divina".

9 El motivo ocurre también en la tradición de Asclepio. Los sirvientes de Asclepio removieron la cabeza de una mujer con el fin de quitar una tenia de ella. Ellos pudieron remover la cabeza pero no fueron capaces de volverla a poner en su lugar. Ante ello, el dios fue provocado y con una efusión de su poder divino fue capaz de poner su cabeza y resucitarla (Ramírez Fueyo, 2011, pp. 132-133).

$10 \mathrm{Al}$ respecto, Maggi (2000, p. 162) afirma que, "al emplear dos términos semejantes en lengua griega, 'generación' ( $\gamma \varepsilon v \varepsilon \dot{\alpha}$, en 9,19) y 'género' ( $\gamma \varepsilon$ Évos, en 9,29), el evangelista une temáticamente la falta de fe de los discípulos y la raza de espíritus mudos y sordos que hay que expulsar". Por su parte, Collins opina que la queja de Jesús pareciese expresar que para él es un agobio estar con "esta generación sin fe" y que anhelara partir (o regresar) hacia el mundo divino (Collins, 2007, p. 437). 
(2012, p. 184) considera que estas palabras ásperas de Jesús, deben ser leídas como dirigidas a los discípulos $(9,19)$. De hecho, Jesús se ha referido antes a los fariseos como "esta generación" $(8,12)$ y más adelante ha descrito el mundo, hostil hacia él y hacia sus discípulos, como una "generación adúltera y pecadora” $(8,38)$. Así, el peligro de que los discípulos se estén pareciendo a "esta generación" (cfr. 8,15) está comenzando a hacerse realidad. Por tal motivo, Pikaza (2012, p. 634) llega a afirmar que "los discípulos de Jesús discuten con los escribas y la multitud $(9,14)$, pero son incapaces de curar al niño (...) porque se han separado de Jesús (de su camino de cruz-pascua) y no consiguen suscitar la fe del padre dolorido (cfr. 9,24) ni despliegan el poder de la oración $(9,29)$ ". Por su parte, Byrne (2008, p.148) considera que, en contraste con los exorcismos anteriores, el núcleo del presente, en la línea del tema central de esta sección del evangelio, está en la incapacidad de los discípulos para remediar la situación a través de la ayuda a un padre cuyo hijo está poseído por un demonio violento. Ellos resultan impotentes para enfrentar este mal debido a que pertenecen a "una generación sin fe" (9v.). Aun a pesar de lo anterior, la breve expresión de enfado y frustración, que prepara la respuesta de Jesús a los discípulos en 9,29, no conduce a Jesús a abandonarles.

De igual modo, la exclamación de Jesús tiene también un amplio trasfondo veterotestamentario: evoca tanto la versión de la Septuaginta de Dt 32,20: "Porque son una generación perversa, hijos en los cuales no hay

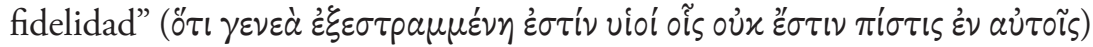
como el salmo 94,10: "Cuarenta años me asqueó aquella generación, dije: Son un pueblo de corazón extraviado que no reconoce mi camino" ( $\tau \varepsilon \sigma \sigma a p a ́ x o v \tau \alpha$

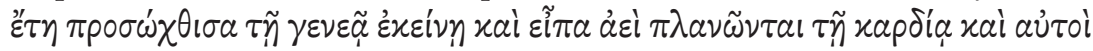

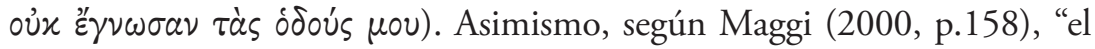
evangelista formula el reproche de Jesús según el modelo que se encuentra en el libro de los Proverbios atribuido a la Sabiduría de Dios: «La sabiduría grita por las calles: ¿Hasta cuándo, inexpertos, amaréis la inexperiencia?» (Prv 1,20-22; Dt 32,5)”. Además, como afirma Marcus (2010),

la queja de Jesús resulta similar a la de Dios ante Moisés en Nm 14 tras el pésimo informe sobre la tierra prometida de los espías israelitas y después de la afirmación del pueblo de que sería más conveniente regresar a Egipto: «¿Cuánto tiempo me despreciará este pueblo? Y ¿Cuánto tiempo rechazarán creer en mí, a pesar de todos los signos que he hecho entre ellos?» ( $\mathrm{Nm}$ 14,11). (p. 755) 
Por su parte, los textos paralelos en Mt 17,7 y Lc 9,41 evocan Dt 32,5

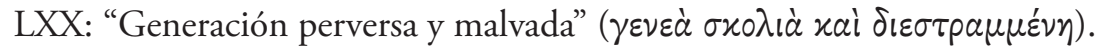
Tales referencias dejan claro que la fe o el creer son el tema clave de este relato marcano (Collins, 2007, p. 437).

Una vez que ha expresado su queja, al final del v.19 Jesús ordena que traigan al muchacho ante él, lo que genera que el espíritu convulsione al poseso, lo arroje a la tierra y lo haga echar espumarajos ${ }^{11}$ en el momento en que VE ( $i \delta \dot{\delta} \nu$, también en participio aoristo, como la multitud que también reacciona al VER a Jesús en el v.15) a Jesús (cfr. v.20). Ante tal hecho resulta llamativa la actitud de Jesús en el v. 21 quien, en lugar de atender inmediatamente al joven, interroga al padre sobre la sintomatología del padecimiento, a la usanza de los médicos griegos. En tal sentido, los lectores/oyentes se pueden ver asociados a la angustia del padre mostrada en el modo como describe los síntomas de su hijo y su grito de desesperación pidiendo fe a Jesús (Byrne, 2008, p.149). De acuerdo con Maggi (2000), en la nueva descripción que da el padre,

los términos clave que pueden ayudar a la comprensión del pasaje son dos: el fuego y el agua, símbolos con los que se representaba a Elías y Moisés, respectivamente (2R 1,10-12; Si 48,1-3; 1R 19,10.14; Ex 2,10; 14,21), los personajes que aparecen con Jesús en el monte de la transfiguración (Mc 9,4) (...). Así, en la situación del muchacho el evangelista representa la condición desesperada del pueblo de Israel, en el cual la doctrina de los escribas alimentaba continuamente la esperanza en el "día de venganza de nuestro Dios" (Is 61,2), una liberación de los enemigos a través de la violencia, como la realizada por Elías y Moisés, recordado este último en la Biblia por 'el gran terror que puso por obra a los ojos de todo Israel' (Dt 34,12). Del mismo modo, en la figura del padre se representa la esperanza suscitada en el pueblo por la alternativa de liberación propuesta por Jesús. (p. 159)

11 Una expresión similar, probablemente inspirada en este relato, se encuentra en el Papiro copto de Utrecht N.1 v.15, escrito alrededor del s. IV d.C, sobre los Hechos apócrifos de Andrés en que se narra que el demonio que posee a un joven "lo arrojó al suelo, y le hizo echar espuma" en el momento en que este llegó a la presencia del apóstol Andrés (Piñero \& Cerro, 2004, p.150). 
Como se ha indicado, el hecho de que el hombre haya llevado su hijo a Jesús es manifestación de su fe, o al menos de su esperanza, de que Jesús tiene el poder de sanar a su hijo. No obstante, la expresión en el v. 22,

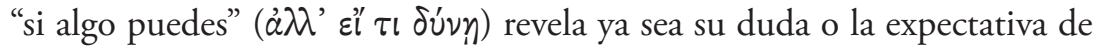
que Jesús vaya más allá de los límites de lo que es humanamente posible (Collins, 2007, p. 438). Dicha expresión evoca las palabras del leproso en

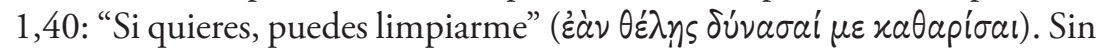
embargo, como señala Marcus (2010, p. 760), "a diferencia del enfermo en 1,40, quien cree que Jesús puede curarlo con solo quererlo, el padre del epiléptico alberga todavía alguna duda residual sobre si Jesús es en realidad capaz de socorrerlo".

La respuesta de Jesús en el v.23, “i¿si puedes?! Todas las cosas son

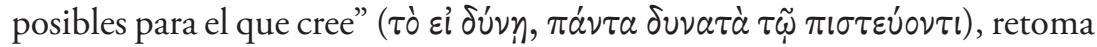
la expresión de la plegaria del padre e invierte los papeles haciendo que la exigencia no sea en torno a la habilidad de Jesús sino a la del padre. De hecho, la expresión de que "todo es posible creyendo" tendría un doble significado: el contexto expresa que "quien cree" en primer lugar es Jesús. A él se ha recurrido por ayuda, si él puede, y como es quien cree, Jesús responde a la esperanza del padre ${ }^{12}$. Pero el sujeto creyente rápidamente comienza a ser también el padre. Así, mientras los discípulos han comenzado a ser arrogantes y obstinado en su propia comprensión (cfr. 6,7-30; 8,32-33), por lo que no han sido capaces de realizar la curación (a pesar de las promesas hechas por Jesús al comienzo, en 3,14-15, y a pesar su eficacia inicial, como en 6,13.30), a través de su grito, en el v.24, el padre proclama su fe, aunque esta sea germinal (Moloney, 2012, p.185). Por ello, el punto climático del relato es el grito del padre, "Creo, jsocorre mi falta fe!" ( $\pi\llcorner\sigma \tau \varepsilon v ́ \omega \cdot \beta о \eta \dot{\theta} \theta \varepsilon$

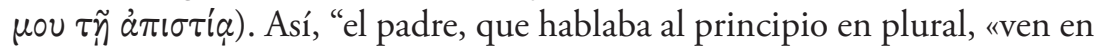
nuestra ayuda...» (v.22), habla ahora en primera persona” ${ }^{13}$. Al respecto, Marcus (2010) asevera que,

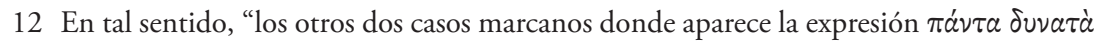
(«todas las cosas son posibles»: 10,27; 14,36) atribuyen la omnipotencia a Dios y no a la capacidad humana, pero el presente relato parece situar a Jesús en una posición análoga a la de Dios" (Marcus, 2010, p. 758).

13 Según Bouyer, "esta es la oración eficaz ofrecida como modelo por Jesús a los discípulos (v.29)” (Bouyer, 2010, p. 45). 
la presentación del padre del muchacho poseído, que tiene y no tiene fe, ha de entenderse probablemente como paradigma de los discípulos que tienen y no tiene fe a la vez, al igual que la descripción del ciego que ve y aún no ve $(8,22-26)$ refleja su visión espiritual imperfecta ${ }^{14}$. (p.753)

Sin embargo, a diferencia de los discípulos, aquí se percibe la ambivalencia entre la decisión del padre de creer y el ir más allá de las fronteras de la limitación humana, por una parte, y su toma de conciencia de que él no puede lograr la curación de su hijo sin la asistencia divina, de otra parte (Collins, 2007, p. 438). Siendo así, como observa Culpepper (2007, p. 321), el padre juega un rol modélico para los discípulos con respecto al tema de la necesidad de una fe constante y creciente. De esta manera, la fe del padre, tal como la fe de la mujer sirofenicia que produjo la liberación de su hija ${ }^{15}$, es el factor crucial en la curación del muchacho ya que, de acuerdo con Collins (2007, p. 438), para el Jesús Marcano, la fe es la condición que puede dotar a los seres humanos con el poder divino ${ }^{16}$. Por ello, como sostiene van Iersel (1998, p. 304), el narrador no está interesado tanto en el muchacho o en el demonio sino en el padre del muchacho y en los discípulos que no pudieron expulsar al demonio.

Sobre la centralidad actancial del padre, a partir del paralelismo propuesto entre este y el relato precedente ("la metamorfosis de Jesús" y "el diálogo con los Tres sobre la venida de Elías") en torno a la relación "acontecimiento"- "explicación privada", resulta sugestiva la analogía que se establece entre la paternidad de este hombre que grita por su hijo incomunicado y el relato precedente de la "metamorfosis" de Jesús $(9,2-8)$

14 Por su parte, Ruis-Camps (2008, p. 201) va más allá del carácter paradigmático del padre con respecto a los discípulos al interior de la trama evangélica y sostiene que, desde el punto de vista del trasfondo histórico de los posibles destinatarios de Marcos, "la relación entre padre e hijo y el hecho que la fe del padre sirve para describir a una comunidad que se ha liberado del espíritu mudo y sordo y ha recuperado su integridad, apuntan que se trata de una comunidad creyente que ha superado su mudez y su sordera".

15 Según Pikaza (2012, p. 643), “en 7,24-30 era la madre la que 'curaba' a Jesús, para que a su vez Jesús curara a la hija de esa madre”.

16 Recuérdese, al respecto, la inhabilidad de Jesús para realizar cualquier acción milagrosa en su tierra natal debido a la falta de fe de sus habitantes (cfr. Mc 6,5-6). 
en que la voz del Padre desde el cielo comunica el amor por su hijo y exhorta a escucharle (cfr. 9,7). En tal sentido, Pikaza (2012) observa que,

nos hallamos ante dos escenas paralelas de paternidad y filiación vinculadas por el mismo Jesús, Hijo divino del monte y el hombre que ayuda al hijo enfermo del valle: Mientras que en el monte está el Padre comunicando expresamente la filiación de su hijo, abajo hay un padre fracasado que no logra comunicarse con su hijo enfermo (cfr. 9,17-24). Así se expresa la tragedia de la humanidad: Un padre incrédulo, un hijo mudo, incomunicados entre sí, entre unos profesionales de la religión (escribas, discípulos) que no saben más que discutir gritando (...). Para curar a su hijo, el padre debe curarse a sí mismo, iniciando un camino de fe, con la ayuda de Jesús (...). La estrategia de Jesús es convertir al padre para que cure al hijo (...). Así, Jesús aparece como 'sanador del padre' con el que dialoga"17. (p. 637 y 641)

En suma, como indica Culpepper (2007, p. 321), el muchacho poseído se encuentra rodeado por cuatro personalidades individuales o colectivas: el padre, los discípulos, los escribas (y la multitud) y Jesús. El padre es incapaz de ayudar a su hijo, sabe que él necesita ayuda y cree que Jesús puede ayudarle. Los discípulos, a quienes desde el inicio se les encomendó expulsar demonios (cfr. 3,15; 6,7) y lo han hecho de forma exitosa (cfr. 6,13), aparentemente han asumido que serían capaces de ayudar al muchacho pero han resultado incompetentes para hacerlo. Los escribas, quienes no realizan ningún esfuerzo para ayudar, discuten con los discípulos. En tal contexto, Jesús responde a las necesidades de los discípulos (mostrándoles cómo es posible ayudar al muchacho), del muchacho (rompiendo las barreras de la incomunicación y la rigidez) y del padre del muchacho (haciéndole capaz de ayudar a su hijo a través de la fe). Y, en palabras de Bouyer (2013, p. 45), "allí donde los discípulos han fracasado, un padre angustiado triunfa".

17 Resaltando esta misma relación narrativa, Bouyer (2013, p. 20) afirma que "La curación del muchacho epiléptico, después de la transfiguración, hace resonar una voz paternal humana: "Te he traído a mi hijo» (Mc 9,17), que se hace eco de la voz paternal divina: «Este es mi hijo amado; escuchadlo» (Mc 9,7)". 


\section{B' Exorcismo (vv.25-27)}

Habiendo tenido lugar la conversación con el padre del muchacho, el exorcismo inicia con el verbo "VER" en participio pasado (i $\delta \dot{\omega} \nu$ ), forma verbal que ha sido transversal en cada uno de los cuadros narrativos del relato (y ha sido referido a los “Tres" en 9,14, a la multitud en 9,15, y al espíritu en 9,20), esta vez teniendo a Jesús como sujeto agente. Así, después de que Jesús se ha percatado de la reaparición de la multitud, reprende al espíritu,

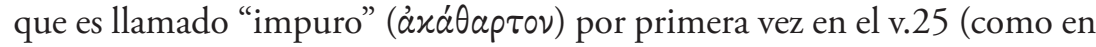
$1,23.26 .27 ; 3,11.30 ; 5,2.8 .13 ; 6,7 ; 7,25)$, como lo hizo en 1,25 , aunque aquí la descripción de la reprimenda de Jesús es más extensa (de hecho, es la más extensa fórmula de exorcismo reportada en los evangelios sinópticos).

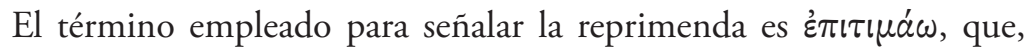
junto con su equivalente hebreo רָָר, son usados tanto en el contexto bíblico como qumrámico con el significado de "destruir, borrar, vencer, pisotear, aturdir, hacer perecer" (ver Gn 37,10; Rt 2,16; Sal 9,6; 68,31; 106,9; 119,21; Is 17,13; 54,9; Jer 29,27; Neh 1,4; Mal 2,3: 3,11) en referencia a la presentación de Dios viniendo como guerrero para juzgar a las naciones extranjeras que han pisoteado a Israel (Horsley, 2001, pp. 137-138). Solamente en una ocasión, el término es usado para hablar de Satán en

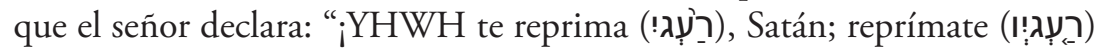
YHWH, el que ha elegido a Jerusalén!” (Za 3,2). En los textos de Qumrán, este término es usado para hablar de la subyugación de los espíritus malvados por parte de Abram o Dios (ver 1QGA) y para referirse a la lucha entre Dios y Belial: "Bendito sea tu nombre, Dios de las mercedes, que haces caer tus gracias sobre nosotros durante el imperio de Belial. En todos los misterios de su hostilidad, no nos ha apartado de tu alianza. Pero sus espíritus de destrucción los has apartado de nosotros cuando maquinaban los hombres de su imperio" (1QM 14,6-7) (García Martínez, 2009, p. 167).

En las palabras del exorcismo, el espíritu es denominado por Jesús como "espíritu mudo y sordo"; dichas condiciones de mudez o sordera ocasionaban que el poseso fuese incapaz de hablar o de escuchar a otros durante una convulsión. Después de la orden dada por Jesús al espíritu de salir y no volver al muchacho, la salida del espíritu en el v.26 es descrita en términos similares a los usados en el primer exorcismo de Jesús (cfr. 1,26). En ambos casos, el espíritu agita fuertemente ( $\pi 0 \lambda \lambda \dot{\alpha} \sigma \pi \alpha \rho \alpha \dot{\xi} \xi \alpha \varsigma)$ a la persona 
poseída y emite un fuerte grito $(\varkappa \rho a ́ \zeta \omega)$ al salir de ella. Incluso siendo el grito inarticulado, tal elemento indica que el espíritu en sí mismo no es mudo sino que causa que su víctima quede mudal (Collins, 2007, p. 439).

A la salida del espíritu, el muchacho parece quedar "como muerto"

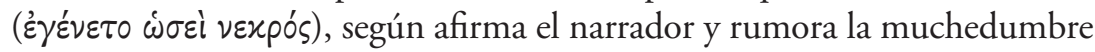
al final del v.26. Las acciones de Jesús de agarrarle de la mano (

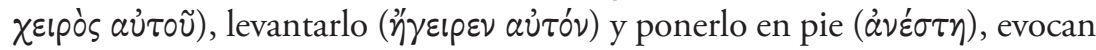
el lenguaje cristiano empleado para referirse a la resurrección (cfr.16, 6) (Moloney, 2012, p. 185) así como ocurre en el relato de la resurrección de la hija de Jairo en que Jesús agarra su mano, le pide que se levante y la pone en pie (5,41-42). En ambos relatos el poder extraordinario de Jesús, realizado gracias a la súplica intercesora de las figuras paternas, es manifestado de forma elocuente (Collins, 2007, p. 439). De este modo, según anota Byrne (2008, p. 150), como en el caso de la hija de Jairo que Jesús levanta (5,35-43), Jesús ha penetrado en el reino de la impureza y la muerte. En un contexto familiar de fe él ha tomado y liberado a una persona joven de las fauces de la muerte, levantándole para hacerle partícipe de su propia vida resucitada.

\section{A'. Conversación privada con los discípulos (vv.28-29)}

En los vv. 28-29 la escena cambia abruptamente de tal modo que Jesús y los discípulos quedan solos. Siguiendo un patrón familiar en el evangelio, los discípulos hacen uso de su asociación íntima con Jesús para preguntarle en privado (cfr. 3,20; 4,10-12.33-34; 7,17) sobre la razón por la cual ellos han sido incapaces de expulsar al demonio. Esta es una típica estrategia marcana en la que la instrucción privada a los discípulos es añadida a los relatos (Collins, 2007, p.439) ocasionando, en este caso, que se transforme el sentido inicial del relato de exorcismo en una lección sobre el discipulado (Culpepper, 2007, p. 321).

Habría de esperarse que la afirmación abierta de Jesús sobre la falta de fe (v.19), la pista de su habilidad para obrar el milagro debido a su unidad en fe con Dios (v.23) y la apertura creyente del padre del muchacho poseído a Jesús (v.24) articuladas en el centro de la perícopa, fuesen el objeto de la respuesta de Jesús (Moloney, 2012, p. 185), subrayando, de esta manera, la necesidad de la fe. Sin embargo, en lugar de ello, él habla de la oración. De 
hecho, es llamativo que el medio recomendado, la oración, no suceda en la historia misma (a no ser que el grito del padre en el v.24 sea considerado como una oración) ${ }^{18}$. En tal sentido, Marcus (2010) afirma que,

la réplica de Jesús suscita tantas preguntas como respuestas ya que Jesús mismo, a pesar de haber prescrito la plegaria como antídoto para el espíritu epiléptico, no aparece rezando antes de expulsar al demonio. Puede ser que haya que sobreentender su rezo, o que Marcos haya ya caracterizado suficientemente a Jesús como un hombre de oración de modo que no necesite hacerlo aquí (cfr. 1,35; 6,46; 14, 32-42). Es asombroso, de todos modos, que en 9,29 Jesús formule una regla para el exorcismo que él mismo no pone en práctica (...). Pero hay un personaje en la historia que sí reza y es el padre del muchacho (...). Las palabras que dirige a Jesús evocan una súplica litúrgica. (pp. 762-763)

De acuerdo con Byrne (2008, p. 150), tal respuesta no es del todo sorprendente si se considera que la oración es un ejercicio básico de la fe y un intento por armonizar la propia vida y acciones con los designios y el poder de Dios. Así, el narrador amplía la brecha entre la falta de fe de los discípulos (v.19) y la fe del padre del muchacho (v.24) pues no hay señal de que los discípulos estén recurriendo a Jesús en sus necesidades (Moloney, 2012, p. 185). Al respecto, Johnson (1979) sugiere que el énfasis Marcano en la confianza vacilante del padre junto con las alusiones a la ceguera de los discípulos indican que sus lectores se encuentran también en una tensión entre la fe y la duda. De este modo, los seguidores de Jesús son instruidos en que en medio de su fe tambaleante la oración del padre debe llegar a ser también la de ellos.

\section{CONCLUSIÓN}

En el contexto narrativo de la sección marcana del camino (Mc 8,27-10,52), justo después de que en un monte un padre (Dios) se ha comunicado con

18 De acuerdo con Collins (2007, p.439), la oración aparece en el Nuevo Testamento como un medio en la realización de obras milagrosas (11,23-24; cfr. St. 5,15; Hch 9,40). 
su hijo (Jesús) y con algunos discípulos de aquel para señalar el amor que le tiene y la necesidad de escucharle $(9,7)$, al bajar del monte se describe, como contraste, la escena de un padre que sufre por la situación de incomunicación de su hijo causada por la acción de un espíritu mudo. De este modo, se ha constatado que la comunicación paterno-filial constituye el eje transversal de las dos escenas y es lo que Jesús, el hijo amado, va a reestablecer en el hijo de aquel padre.

Y a pesar de que este padre ha recurrido al resto de los discípulos de Jesús, estos, que antes se mostraban exitosos por su capacidad exorcista (ver Mc 6,12), ahora aparecen incapaces de realizar la liberación. El relato, que sigue un patrón narrativo común con respecto a los relatos marcanos de curación en los que quienes padecen la afección tienen la condición de hijos/ hijas y quienes ejercen el rol de interceder por el enfermo son sus padre/ madres, muestra que la causa de tal fracaso tiene relación con la falta de fe (Mc 9, 19.23-24) y de oración (v.29). En contraste con los discípulos, la súplica ferviente del padre, que pide acrecentar su fe, resulta ser un desafío para los discípulos cuya poca fe no les permitió curar al muchacho.

\section{LISTA DE REFERENCIAS}

Bouyer, V. (2013). Personajes anónimos del Evangelio. Encuentros de Jesús en los evangelios sinópticos. CB 160. Estella: Verbo Divino

Bultmann, R. (2000). Historia de la tradición sinóptica. Salamanca: Sígueme.

Byrne, B. (2008). A Costly Freedom: A theological Reading of Mark's Gospel. Collegeville: Liturgical Press.

Collins, A.Y. (2007). Mark: A Commentary. Minneapolis: Fortress.

Culpepper, R.A. (2007). Mark. Macon: Smyth \& Helwys Pub.

Donahue J. \& Harrington, D. (2002). The Gospel of Mark. Collegeville: Liturgical Press.

García Martínez, F. (2009). Textos de Qumrán. Madrid: Trotta.

Horsley, R. (2001). Hearing the Whole Story: The Politics of Plot in Mark's Gospel. Louisville: Westminster John Knox Press. 
Iersel, B.M.F. (1998). Mark: A Reader-Response Commentary. Sheffield: Sheffield Academic Press.

Johnson, E. (1979). "Mark VIII 22-26: The Blind Man from Bethsaida”. New Testament Studies 25, 370-383.

Maggi, A. (2000). Jesús y Belcebú: Satán y demonios en el evangelio de Marcos. Bilbao: Desclée de Brower.

Marcus, J. (2010). El evangelio según Marcos (8-16). Salamanca: Sígueme.

Metzger, B. (ed.). (2000). The Greek New Testament. Stuttgart: Deutsche Bibelgesellschaft.

. (2006). Un comentario textual al Nuevo Testamento Griego. Sao Paulo: Sociedades Bíblicas Unidas.

Moloney, F. (2012). The Gospel of Mark: A commentary. Grand Rapids: Baker Academic.

Nestle, E \& Aland, K (Edit.). (2012). Novum Testamentum Graece. Stuttgart: Deutsche Bibelgesellschaft.

Noratto Gutiérrez, J. (2013). El lenguaje de las manifestaciones del resucitado y su sentido a partir de los textos fundamentales del Nuevo Testamento. Cuestiones Teológicas, 40 (94), 289-322.

Pikaza, X. (2012). Evangelio de Marcos: La buena noticia de Jesús. Estella: Verbo Divino.

Piñero, A. \& Cerro, G. (2004). Hechos Apócrifos de los Apóstoles. Vol I: Hechos de Andrés, Juan y Pedro. Madrid: Biblioteca de Autores Cristianos.

Prieto Fernández, F.J. (2009). Las figuras cambiantes de Jesús en la literatura cristiana antigua. Salamanca: Universidad Pontificia de Salamanca.

Ramírez Fueyo, F (2011). Dolor, enfermedad y muerte en el Nuevo Testamento. En F. J. De la Torre Díaz (Edit.). Enfermedad, dolor y muerte desde las tradiciones judeocristiana y musulmana, 117-140. Madrid: Universidad Pontificia de Comillas.

Ruis-Camps, J. (2008). El Evangelio de Marcos Etapas de su redacción. Redacción jerosolimitana, refundición a partir de Chipre, redacción final en Roma o Alejandría. Estella: Verbo Divino. 